\title{
Seasonal variation and time trends of deaths from asthma in England and Wales 1960-82
}

\author{
A KHOT, R BURN
}

\begin{abstract}
Monthly trends in deaths attributed to asthma in the 5-34 year age group were examined for England and Wales over the period 1960-82. Deaths were most frequent in the third quarter (July to September) and peaked in August. Analysis of the 1970-82 period showed that this variation was present in the three constituent age groups 5-14, 15-24, and 25-34 but was most pronounced in the 5-14 year olds.
\end{abstract}

\section{Introduction}

Despite improvements in treatment, increased awareness, and easier access to hospital, the mortality from asthma has altered little since the transient rise in the 1960s. ${ }^{1}$ The recent report $^{2}$ from New Zealand of an increase in mortality from asthma during the late 1970s is a cause for concern.

Although a seasonal variation in mortality has been noted before, ${ }^{1}$ it has received little attention. This study aimed at identifying the seasonal profile of deaths from asthma in the 5-34 year age group.

Royal Alexandra Hospital for Sick Children, Brighton BN1 3JN A KHOT, MB, DCH, research associate

Brighton Polytechnic, Moulscoomb, Brighton

R BURN, MSC, FSS, statistician

Correspondence to: Dr A Khot.

\section{Method}

Monthly asthma mortality data for the 5-34 year age group in England and Wales for the period 1960-82 were obtained from the Office of Population Censuses and Surveys. A further breakdown into age groups 5-14, 15-24, and 25-34 years was available for the period 1970-82. Mid-year population estimates were obtained from the Office of Population Censuses and Surveys.

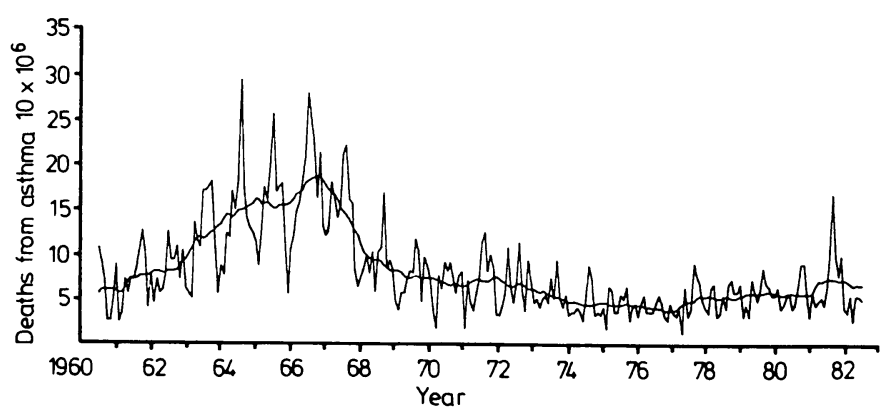

FIG 1-Monthly mortality rates for asthma (age 5-34 years), with superimposed trend, in England and Wales 1960-82 (source: Office of Population Censuses and Surveys).

There were two revisions of the International Classification of Diseases (ICD); in 1968 coexistent emphysema was excluded, and in 1978 bronchitis with mention of asthma was included. These revisions were unlikely to have influenced the mortality from asthma in the 5-34 year age group. ${ }^{2}$

The statistical method used was as described. ${ }^{3}$ This method was applied to the following series: deaths from asthma per million during 1960-82 (age 5-34 years) and deaths from asthma per million during 1970-82 (age 5-14, 15-24, and 25-34 years). The population data used were mid-year estimates obtained from the Office of Population Censuses and Surveys. 


\section{Results}

Figure 1 shows the monthly mortality and trend for the 5-34 year age group (1960-82). Since the well documented increase in mortality in the 1960 s there had been little alteration in trend, the average monthly death rate remaining at around 6 per 10 million. A minimal upward drift was observed in the last few years.

Figure 2 shows the average monthly percentage variation about the trend for this series. The most striking feature of the seasonal variation was the increase in mortality in the third quarter (July to September), peaking at $45 \%$ above the trend in August. By contrast, deaths from asthma were least frequent in the first quarter.

Analysis of the 1970-82 data by age group (fig 3) showed that all three age groups had a similar seasonal variation. The August peak, however, was most pronounced in the 5-14 year olds.

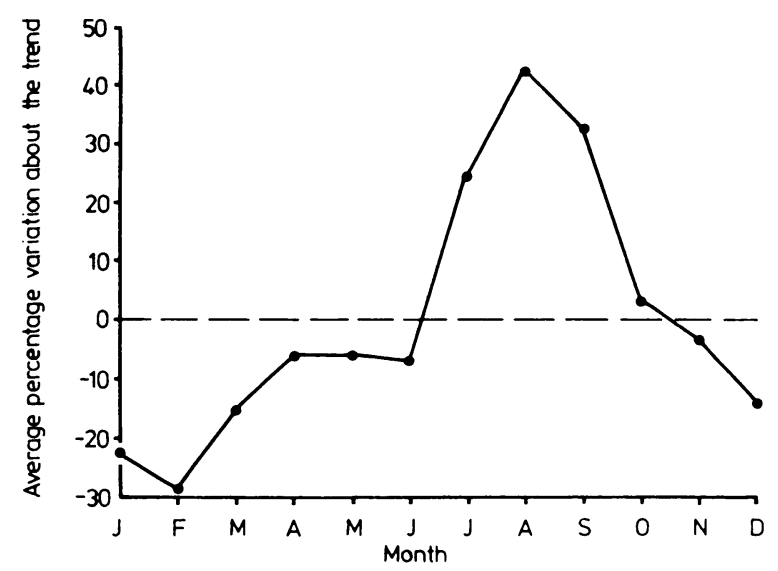

FIG 2-Average monthly variation in deaths from asthma in 5-34 year age group in England and Wales 1960-82.

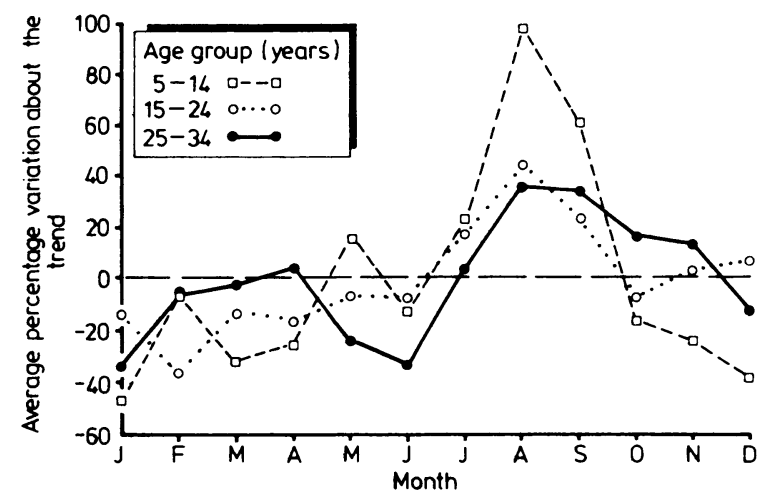

FIG 3-Average monthly variations in deaths from asthma in age groups 5-14, 15-24, and 25-34 years in England and $W$ ales 1970-82.

\section{Discussion}

Our finding that deaths from asthma are not evenly distributed throughout the year but show a seasonal variation agrees with a previous report. ${ }^{1}$ The increase in mortality in the third quarter (July to September) with a peak in August was observed in all three age groups but was most pronounced in the 5-14 year olds. This latter observation was in sharp contrast with the decrease in admissions for asthma in August in the same age group. ${ }^{3}$ The estimated seasonal variation about the trend indicates that during the past 15 years the average monthly mortality had ranged from roughly 4 per 10 million in February to 9 per 10 million in August. The significance of the minimal upward drift in the past few years is difficult to assess, but it was unlike the pronounced increase noted in New Zealand. ${ }^{2}$

The circumstances that precede death from asthma have recently been reviewed. ${ }^{4}$ The majority of deaths occur in patients with severe chronic asthma; in these patients the final deterioration may be rapid, ${ }^{5-7}$ although in most cases there is a background of decreasing function. ${ }^{8-10}$ Furthermore, inadequate assessment and treatment are common, large numbers of deaths occurring outside hospital.?

The seasonal variation may be a reflection of several factors. Inhaled allergens are common during the summer and may contribute to a worsening of asthma. Although the main grass pollen season occurs before the peak in mortality, there is evidence that allergen challenge not only causes a direct response (early and late reactions) but also results in a non-specific increase in bronchial reactivity. ${ }^{112}$ Other environmental triggers may then provoke the fatal attack. Fungal spores are common at that time but their role in precipitating asthma is uncertain. Little is known about the patterns of consultation in July and August, and reticence in seeking attention during these holiday months may contribute.

There may exist a subset of the "at risk" population who are seasonally vulnerable, and further research is necessary to evaluate the role of exogenous triggers and social and medical care factors in the seasonal variation of mortality from asthma.

The material supplied by the Office of Population Censuses and Surveys is reproduced with the permission of the Controller of Her Majesty's Stationery Office. We thank the staff of the medical statistics department of the Office of Population Censuses and Surveys for their cooperation.

AK is supported by a grant from the Royal Alexandra Children's Hospital Centenary Fund, Brighton. Support has also been obtained from the South East Thames Regional Health Authority through the LORS fund. We are grateful to both these funds.

\section{References}

' Inman WHW, Adelstein AM. Rise and fall of asthma mortality in England and Wales in relation to the use of pressurised aerosols. Lancet 1969;ii:279-85.

2 Jackson RT, Beaglehole R, Rea HH, Sutherland DC. Mortality from asthma: a new epidemic in New Zealand. $\mathrm{Br}$ Med $\mathcal{F} 1982 ; 285: 771-4$

${ }^{3}$ Khot A, Burn R, Evans N, Lenney C, Lenney W. Seasonal variation and time trends in childhood asthma in England and Wales $1975-81$. Br Med $\mathcal{F} 1984 ; 289$ : 235-7.

- Cushley MJ, Tattersfield AE. Sudden death in asthma: discussion paper. $₹ R$ Soc Med 1983;76:662-6

Macdonald JB, Seaton A, Williams DA. Asthma deaths in Cardiff 1963-74: 90 deaths outside hospital. Br Med f 1976;1:1493-5.

ritish Thoracic Association. Death from asthma in two regions of England. $B r$ Med f 1982;285:1251-5.

Ormerod LP, Stableforth DE. Asthma mortality in Birmingham 1975-7: 53 deaths. Br Med f 1980;280:687-90.

Macdonald JB, Macdonald ET, Seaton A, Wiliams A. Asthma deaths in Cardif 1963-74: 53 deaths in hospital. Br Med $\mathcal{O} 1976$;ii:721-3.

- Bellamy D, Collins JV. Acute asthma in adults. Thorax 1979;34:36-9.

Davis B, Gett PM, Sherwood-Jones E. A service for the adult asthmatic. Thorax 1980;35:111-3.

"Altounyan REC. Changes in histamine and atropine responsiveness as a guide to diagnosis and evaluation of therapy in obstructive airways disease. In: Pepys $J$, Frankland AW, eds. Disodium cromoglycate in allergic airways disease. London:

12 Boulet L-P, Cartier A, Thomson NC, Roberts RS, Dolovich J, Hargreave FE. Asthma and increases in non-allergic bronchial responsiveness from seasonal pollen exposure. $\mathcal{F}$ Allergy Clin Immunol 1983;71:399-406.

(Accepted 10 May 1984)

A young man reports that for the past six months he has had episodes (once or twice a week) when he has woken at night to find his mouth filling with a tasteless colourless fluid which comes from beneath the tongue, and may be sufficient in quantity to fill a cup. He has no indigestion, smokes 20-30 cigarettes a day, and admits to drinking "too much" alcohol. What could this phenomenon be due to?

He is experiencing waterbrash, a sudden flow of watery saliva. This is a phenomenon of undetermined mechanism experienced by some dyspeptic patients. One stimulus to the increased flow of saliva is irritation of the lower oesophagus, and gastrooesophageal reflux is known to cause waterbrash. Possibly this man has gastrooesophageal reflux without heartburn, and smoking, alcohol, and recumbency are major causative factors.-JOHN BENNETT, consultant physician, Kingston upon Hull. 